University of Warwick institutional repository: http://go.warwick.ac.uk/wrap

This paper is made available online in accordance with publisher policies. Please scroll down to view the document itself. Please refer to the repository record for this item and our policy information available from the repository home page for further information.

To see the final version of this paper please visit the publisher's website. Access to the published version may require a subscription.

Author(s): Parsons, Nicholas R., Odumenya, M., Edwards, A., Lecky, F. and Pattison, G.

Article Title: Modelling the effects of the weather on admissions to UK trauma units: a cross-sectional study

Year of publication: 2011

Link to published article:

http://dx.doi.org/10.1136/emj.2010.091058

Publisher statement: (C) Emergency Medical Journal and BMJ Publishing group. Parsons, Nicholas R., Odumenya, M., et al. (2011). Modelling the effects of the weather on admissions to UK trauma units: a cross-sectional study, 28(10), pp. 851-855. 


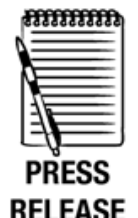

- Additional material is published online only. To view these files please visit the journal online (http://emj.bmj. com).

${ }^{1}$ Warwick Medical School, University of Warwick, Coventry, UK

${ }^{2}$ University Hospitals of Coventry and Warwickshire NHS Trust, Coventry, UK ${ }^{3}$ The Trauma Audit and Research Network, University of Manchester, Manchester Medical Academic Health Sciences Centre, Clinical Sciences Building, Hope Hospital, Salford, UK

\section{Correspondence to} Dr Nick Parsons, Warwick Medical School, University of Warwick, Coventry, CV4 7AL, UK;

nick.parsons@warwick.ac.uk

Accepted 10 August 2010 Published Online First 22 November 2010

\title{
Modelling the effects of the weather on admissions to UK trauma units: a cross-sectional study
}

\author{
Nick Parsons, ${ }^{1}$ Michelle Odumenya, ${ }^{1,2}$ Antoinette Edwards, ${ }^{3}$ Fiona Lecky, ${ }^{3}$ \\ Giles Pattison ${ }^{1,2}$
}

\begin{abstract}
Objective To assess the relationship between daily trauma admissions and observed weather variables, using data from the Trauma Audit and Research Network of England and Wales and the UK Meteorological Office.

Design A cross-sectional study.

Setting Twenty-one accident and emergency

departments (ED) located across England.
\end{abstract}

Participants All patients arriving at one of the selected $E D$, with a subsequent death, inpatient stay of greater than 3 days, interhospital transfer or requiring critical care between 1 January 1996 and 31 December 2006. Main Outcome Measures Daily counts of adult and paediatric trauma admissions.

Results Multivariate regression analysis indicated that there were strong seasonal trends in paediatric $\left(\chi^{2}\right.$ likelihood ratio test $p<0.001)$, and adult $(p=0.016)$ trauma admissions. For adults, each rise of $5^{\circ} \mathrm{C}$ in the maximum daily temperature and each additional $2 \mathrm{~h}$ of sunshine caused increases in trauma admissions of $1.8 \%$ and $1.9 \%$. Effects in the paediatric group were considerably larger, with similar increases in temperature and hours of sunshine causing increases in trauma admissions of $10 \%$ and $6 \%$. Each drop of $5{ }^{\circ} \mathrm{C}$ in the minimum daily temperature, eg, due to a severe night time frost, caused adult trauma admissions to increase by $3.2 \%$. Also the presence of snow increased adult trauma admissions by $7.9 \%$.

Conclusion This is the largest study of its kind to investigate and quantify the relationship between trauma admissions and the weather. The results show clear associations that have direct application for planning and resource management in UK ED.

It is a widely held belief that the number of trauma admissions by accident and emergency departments (ED) is related to the local weather conditions. It is believed that certain weather patterns, such as warm sunny days or heavy rainfall are associated with greater numbers of trauma admissions; due to, for instance, an increase in outdoor activity in the former case and an increase in road traffic collisions (RTC) in the latter case. A strong positive correlation has been previously reported between monthly sunshine hours and paediatric fractures, ${ }^{1}$ suggesting that longer hours of outdoor activity lead directly to an increased exposure to potential situations likely to lead to traumatic injury. Also, results from another preliminary study showed that seasonal patterns of weather-related RTC in England and Wales match the occurrence of hazardous conditions, with regional variations to weather patterns identifiable within RTC data. ${ }^{2}$ Others have attempted to model the relationship between meteorological factors and trauma admissions ${ }^{34}$ and motor vehicle collisions; ${ }^{5}$ and more specifically between meteorological factors and paediatric admissions. ${ }^{6}$ The most comprehensive reported study to date used one year's data from Leicester Royal Infirmary and established significant associations between daily trauma admissions and local weather conditions. ${ }^{7}$ That study, along with much of the literature reported in this area, has provided reasonable evidence for associations between the weather and trauma admissions. However, that work has not led to changes in the planning of care provision in trauma units, due perhaps partly to the perceived weakness of the evidence provided by such studies; most of the work used short time periods and single study centres.

The suggestion that weather reports could be used to help forecast NHS workloads is not new, ${ }^{89}$ and the potential to predict variability in admission numbers to trauma units to assist in planning is clear, despite reservations about the current reliability of short to medium-term weather forecasts. Irrespective of the potential exploitation of models for planning purposes, it seems important first to explore fully, quantify and understand the nature of the relationship between recorded weather data and trauma counts. To this end, we have acquired comprehensive records of trauma admissions for an 11-year period (1996-2006) from a representative sample of hospital centres from the Trauma Audit and Research Network (TARN) of England and Wales. Together with corresponding weather records provided by the UK Meteorological Office, we construct and report on the significance of models relating trauma admission counts to recorded weather variables. Previous work has shown that paediatric admissions are likely to be considerably more sensitive to variability in the weather ${ }^{7}$; therefore we have developed models for adults and paediatric admissions separately. This is a cross-sectional study that matches daily trauma admission count data, obtained from a representative sample of hospitals, to a range of weather variables recorded locally to the incident hospital. The aim of the study is to establish and quantify the significance of relationships between trauma admission counts and the weather, and draw inferences on the observed effects more widely for UK trauma services.

\section{METHODS \\ TARN data}

Data reporting injured patients admitted to hospital after attending ED, for the period 1 January 1996 until 31 December 2006, were 
obtained from TARN for 21 core hospital centres in England. TARN captures data from patients arriving at hospital alive after injury and fulfilling one or more of the following four criteria: (1) the patient subsequently died as a result of the injury; (2) the patient received interhospital transfer; (3) the patient required critical care and (4) the inpatient stay was greater than 3 days. The proportion of patients arriving at hospital after receiving interhospital transfer was approximately $10 \%$, across all 21 core hospital centres. TARN excluded neck of femur fractures from patients aged over 65 years and unilateral closed limb fractures. The hospitals selected provided consistent and reliable submission records and were of varying size and geographical location, covering both urban and rural areas, and as such were generally representative of the UK population (details of locations are in the supplementary material, available online only). The data available for each patient admitted to one of the selected centres during the study period were age (years), gender, injury severity score, date of attending ED and date of injury. In total there were 59167 patient records, after validation and data cleaning (see supplementary material, available online only, for details), the numbers categorised by injury severity score, patient status (alive or dead) and mechanism of injury for adult and paediatric groups (age less than 16 years) are shown in table 1.

\section{Weather data}

Weather data for the period 1 January 1996 until 31 December 2006 were obtained from the UK Meteorological Office, reporting observations made at the nearest meteorological stations to each of the 21 selected centres (see supplementary material, available online only, for details). The data consisted of daily measurements of maximum and minimum temperatures $\left({ }^{\circ} \mathrm{C}\right)$, rainfall $(\mathrm{mm})$, sunshine $(\mathrm{h})$, mean wind speed $(\mathrm{mph})$ and maximum gust wind speed ( $\mathrm{mph}$ ) and the presence or absence of snow or sleet and fog. These particular variables were selected predominantly because they are the most widely reported elsewhere, but also because they are all currently provided by the UK Meteorological Office's numerical weather forecast. Data

Table 1 Trauma admission counts by patient status (dead/alive), ISS and mechanism of injury after treatment for adult and paediatric groups

\begin{tabular}{|c|c|c|c|c|c|}
\hline \multirow[b]{2}{*}{ Mechanism of injury } & \multicolumn{2}{|c|}{ ISS $\leq 15$} & \multicolumn{2}{|c|}{ ISS $>15$} & \multirow[b]{2}{*}{ Total (\%) } \\
\hline & Alive & Dead & Alive & Dead & \\
\hline \multicolumn{6}{|l|}{ Adult } \\
\hline Amputation (partial) & 10 & 0 & 0 & 0 & $10(0.02)$ \\
\hline Amputation (total) & 6 & 0 & 0 & 0 & $6(0.01)$ \\
\hline Burn & 32 & 0 & 12 & 7 & $51(0.10)$ \\
\hline Fall less than $2 \mathrm{~m}$ & 19384 & 576 & 1243 & 399 & $21602(40.68)$ \\
\hline Fall more than $2 \mathrm{~m}$ & 4569 & 64 & 1710 & 545 & $6888(12.97)$ \\
\hline Other & 5297 & 48 & 905 & 244 & $6494(12.23)$ \\
\hline Skeletal/organ/vessel destruction & 9 & 0 & 5 & 0 & $14(0.03)$ \\
\hline Vehicle incident/collision & 11266 & 139 & 5118 & 1516 & $18039(33.97)$ \\
\hline \multicolumn{6}{|l|}{ Paediatric } \\
\hline Amputation (partial) & 1 & 0 & 0 & 0 & $1(0.02)$ \\
\hline Amputation (total) & 0 & 0 & 0 & 0 & $0(0.00)$ \\
\hline Burn & 21 & 0 & 1 & 0 & $22(0.36)$ \\
\hline Fall less than $2 \mathrm{~m}$ & 1303 & 1 & 140 & 9 & $1453(23.97)$ \\
\hline Fall more than $2 \mathrm{~m}$ & 465 & 0 & 189 & 23 & $677(11.17)$ \\
\hline Other & 1062 & 6 & 209 & 31 & $1308(21.57)$ \\
\hline Skeletal/organ/vessel destruction & 0 & 0 & 0 & 0 & $0(0.00)$ \\
\hline Vehicle incident/collision & 1632 & 4 & 811 & 155 & $2602(42.92)$ \\
\hline Total & 45057 & 838 & 10343 & 2929 & 59167 \\
\hline
\end{tabular}

'Other' indicated mechanisms of injury not covered by the other categories; for example sports-related injury.

ISS, injury severity score. were missing for a number of these variables at specific sites and days, due predominantly to instrument-related technical failure, amounting to $7.5 \%$ of the full dataset. The available data are summarised by week number by averaging across years and hospital centres in figure 1.

\section{Statistical models}

The default choice for modelling count data is the Poisson distribution, implemented in the Poisson regression model. ${ }^{10}$ However, when, as is often the case, counts are suspected of being overdispersed, the presence of greater variability than would be expected for the selected model, the most common extension is to the negative binomial distribution. ${ }^{11}$ Previous work has shown the negative binomial distribution to be a useful model for trauma admission counts. ${ }^{4}$ Trauma counts are expected to exhibit a degree of clustering, due to for instance multiple individuals being involved in a single event (eg, a motor vehicle accident), and therefore in principle one would expect the negative binomial distribution to be the most appropriate model for these data.

Negative binomial regression models ${ }^{12}$ were fitted to observed daily adult and paediatric group trauma admission counts using the yearly counts at each centre and year as a model offset (see supplementary material, available online only, for full description of the model). This effectively transforms the model response into the daily admission rate relative to the total yearly admission count for each centre and year; removing the effects of centre and year that would otherwise be problematical. The weather variables were used as explanatory variables in the regression model together with seasonal factors representing the day of the week and the week number and also a factor indicating significant days, such as public and school holidays. When there were missing weather data, then reported analyses used complete cases only. Modelling work was undertaken in the $\mathrm{R}$ statistical software $^{13}$ using available negative binomial functions. ${ }^{14}$

\section{RESULTS}

A total of 59617 patients was included in the study; the median age of adult and paediatric patients was, respectively, 47.8 years (range 16-110) and 9.7 years (0-15). Mean daily trauma admissions were 0.839 patients per hospital centre, with a range from 0 to 10 . Indeed, across all hospital centres and years the most likely daily admission count was 0 , occurring $49.6 \%$ of the time. Initially, as a way of investigating the crude seasonal variation in trauma counts during the course of a year, a regression model was fitted including only a factor indicating the week number; in which Monday was designated as the first day of the week and the first Monday of the year as day 1 of week 1. Incidence rate ratios (IRR) indicated the strength of the association; for instance an IRR of 1.2 indicates a $20 \%$ increase in the incidence of trauma admission relative to the baseline group, in which the IRR is set to unity. Estimates of IRR for each week, with week 1 set to unity, are shown in figure 2, together with a cubic spline curve (with degrees of freedom equal to 4) for both the adult and the paediatric group, to indicate the overall seasonal trend. A likelihood ratio test indicated that the model including the cubic spline term for week number was a significant improvement on the null model (model with no explanatory variables) for the paediatric group ( $\chi^{2}$ likelihood ratio test $\mathrm{p}<0.001)$, and for the adult group $\left(\chi^{2}\right.$ likelihood ratio test $\mathrm{p}=0.016)$. Figure 2 indicates that trauma admissions were approximately $70 \%$ higher during the peak of the summer season than at the beginning of the year in the paediatric group, irrespective of year or hospital. This confirms the peak in 
Figure 1 Weekly trends in recorded mean weather data for the period 1 January 1996 to 31 December 2006 and for the selected hospital centres.

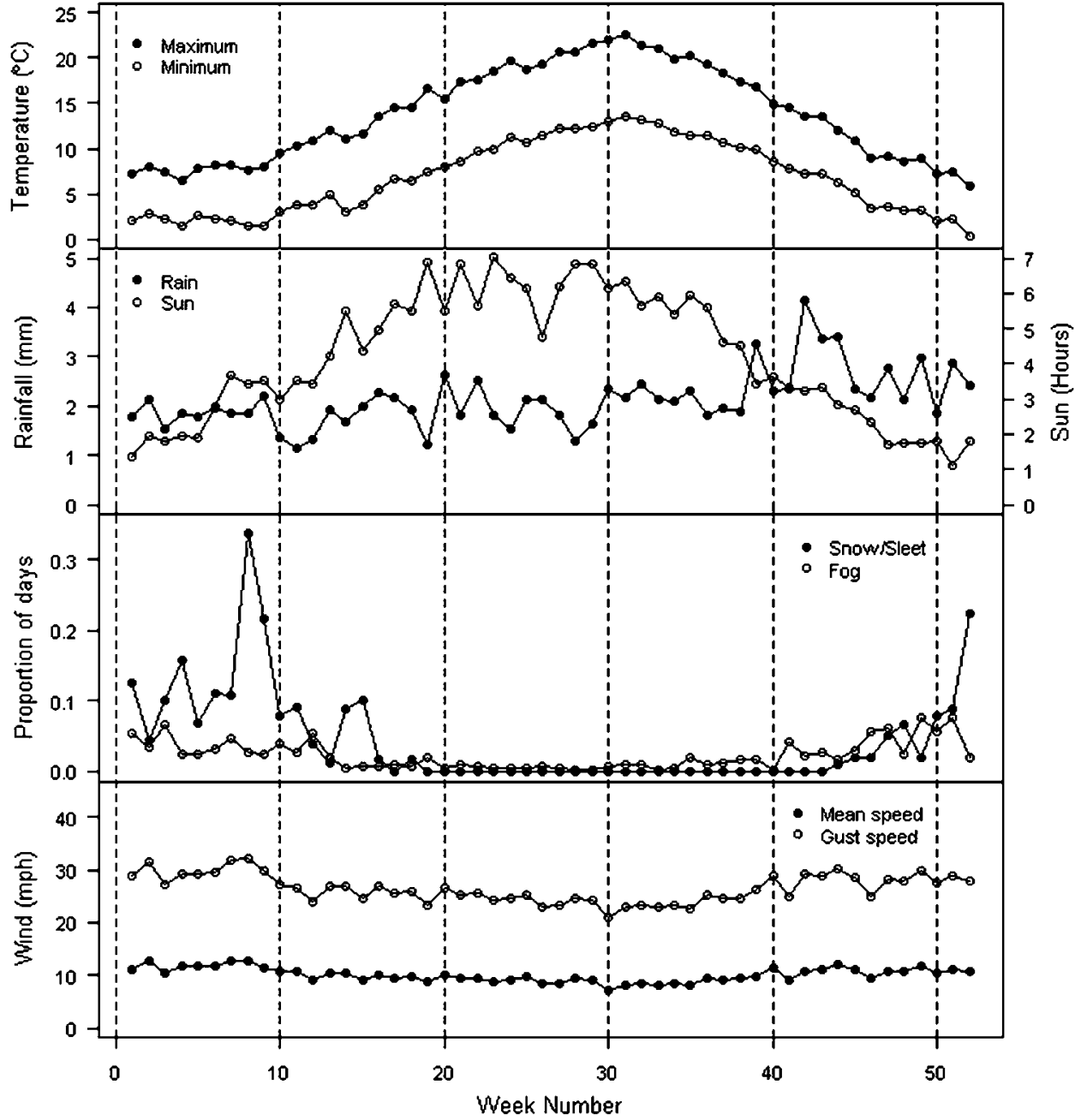

admissions during the summer months for this group of patients reported elsewhere. ${ }^{7}$ Adult trauma admission also showed some significant seasonal variation, but without the marked rise during the summer months seen for the paediatric group.

Multivariate regression models for adult and paediatric admission counts were developed using stepwise regression, with forward selection and backward elimination, to select a subset of significant model terms using Akaike's information criterion. ${ }^{15}$ For the paediatric model the important terms were the day of the week, an indication of a public or school holiday, the maximum daily temperature, the number of hours of sunshine and the mean and maximum gust wind speed. For the adult model the important terms were the day of the week, the maximum and minimum daily temperature, the number of hours of sunshine, the daily rainfall and the presence of snow. The parameter estimates (table 2) were such that for both paediatric and adult patients the peak in trauma admission occurred on Saturdays, with a low number of admissions occurring on Tuesdays, followed by a gradual increase from this day of the week until the weekend. The estimated IRR indicated an increased incidence of trauma admissions of approximately $11 \%$ and $4 \%$ for the adult and paediatric groups for Saturday relative to Friday; similarly trauma admissions on Tuesdays were $16 \%$ and $19 \%$ lower for the adult and paediatric groups. Also, for the paediatric group, an indication that the day was a public or school holiday also significantly increased admission by an estimated $6 \%$.

The incidence of both adult and paediatric admissions increased as the maximum daily temperature and the hours of sunshine increased. For the adult group, each rise of $5^{\circ} \mathrm{C}$ in the maximum daily temperature and each additional $2 \mathrm{~h}$ of sunshine caused increases in trauma admissions of $1.8 \%$ and $1.9 \%$, respectively. The effects in the paediatric group were considerably larger, with similar increases in temperature and hours of sunshine causing increases in trauma incidence of $10 \%$ and $6 \%$, respectively. For the adult group, adverse weather conditions appeared to be important in increasing trauma admissions in a manner that was not observed for the paediatric group. The minimum daily temperature proved to have an important effect on adult trauma admissions, with each drop of $5^{\circ} \mathrm{C}$, for instance due to a severe night time frost, causing admissions to increase by $3.2 \%$. The presence of snow or sleet increased adult trauma admissions by $7.9 \%$ and each additional $10 \mathrm{~mm}$ of rainfall increased trauma admissions by $2.2 \%$. The effects of wind on trauma admissions were important for the paediatric group only. As the maximum wind gust speed was generally at least twice the mean speed (figure 1), estimated IRR for these two factors suggest that an approximate $20 \mathrm{mph}$ increase in the mean wind speed would cause a decline in paediatric trauma incidence of $13 \%$.

\section{DISCUSSION}

This is a large retrospective analysis of prospectively recorded data that correlates daily trauma admissions for adult and paediatric patients with prevailing local weather conditions on the day the injury was sustained. It provides clear evidence that paediatric trauma admissions increase during the summer 


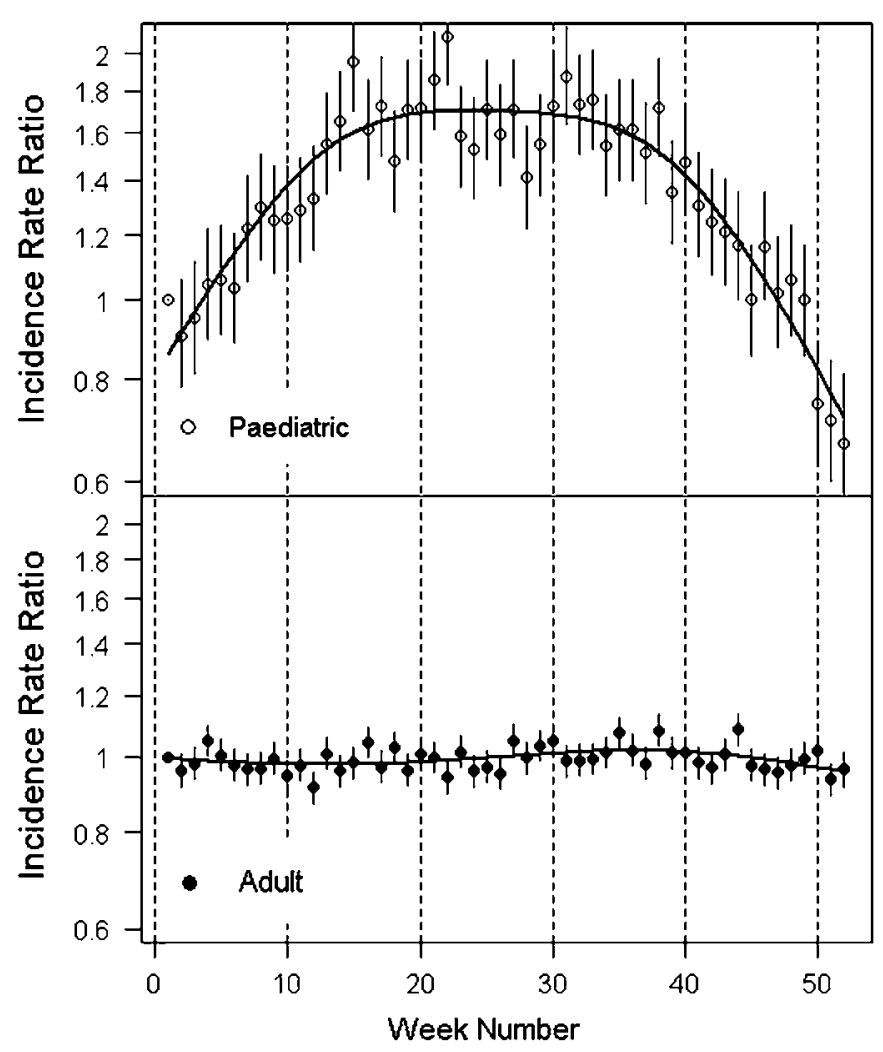

Figure 2 Incidence rate ratios and fitted splines ( $\pm 1 \mathrm{SE}$ ) to indicate week-to-week (seasonal) variation in admission counts for adult (O) and paediatric $(O)$ patients.

months (figure 1); our data suggest that this increase could be of the order of $50 \%$ during the period from April to September. Previous studies report a comparable increase of 30\% for paediatric trauma admissions for this period by an ED in the north east of Scotland and provide evidence that paediatric admissions are more strongly related to 'good' weather than 'bad' weather conditions. $^{6} 16$ This was confirmed in a year-long study in Leicester that found that a $5^{\circ} \mathrm{C}$ increase in maximum daily temperature increased paediatric trauma admissions by $11 \%$, and that each additional hour of sunshine increased admissions by $4 \%{ }^{7}$ The comparable figures from our study for the effects of maximum temperature and sunshine, from an 11-year period for 21 centres, were $10 \%$ and $3 \%$; remarkably similar estimates. The assumption is that children playing outdoors are more likely to sustain trauma injuries, ${ }^{17}$ and that the increased opportunity for this during the summer months results in the reported seasonal trends for this population. Our study, which is by some way the largest of its kind, clearly demonstrates the strong association between weather conditions and seasonal increases in paediatric trauma admissions.

The observed day of the week effects, with a peak in admissions at the weekend, appeared to be consistent with the hypothesis that increased outdoor activity correlated well with increases in both adult and paediatric admissions. Previous work also reports that trauma admissions were considerably higher at the weekend; with estimates suggesting that trauma admissions increased by $24 \%$ on Saturdays, relative to the average day. ${ }^{3}$ Adult trauma admissions did not show the marked increase during the summer months apparent for paediatric admissions. As for paediatric admissions, the effects of increased maximum daily temperature and sunshine were significant, but of a much smaller magnitude for adult admissions. Strong associations between high temperature and the occurrence of trauma have been reported elsewhere, with the authors speculating that this was due to increases in outdoor activity and driving. ${ }^{5}$ This increase in summer outdoor activity-related trauma admissions for adults seems to be in a sense balanced by the increase in admissions due to 'bad' weather conditions in the winter months for this population; resulting in the lack of a strong seasonal trend for adults (figure 2). The increase in adult admissions observed for our data due to heavy precipitation have also been reported previously in Tokyo and at a large US trauma unit. ${ }^{4}$ However, the strong associations reported in our study linking the effects of falling temperatures, presumably an

Table 2 Final fitted models for seasonal factors and weather variables, showing IRR, $95 \% \mathrm{Cl}$ and associated $p$ values for adult (residual d.f. 48 405) and paediatric (residual d.f. 54 524) group models

\begin{tabular}{|c|c|c|c|c|c|c|}
\hline \multirow[b]{2}{*}{ Model term } & \multicolumn{3}{|l|}{ Adult } & \multicolumn{3}{|c|}{ Paediatric } \\
\hline & IRR & $95 \% \mathrm{Cl}$ & p Value & IRR & $95 \% \mathrm{Cl}$ & p Value \\
\hline \multicolumn{7}{|l|}{ Seasonal } \\
\hline \multicolumn{7}{|l|}{ Weekday } \\
\hline Monday & 0.868 & (0.836 to 0.902$)$ & $<0.001$ & 0.833 & (0.751 to 0.924$)$ & $<0.001$ \\
\hline Tuesday & 0.843 & (0.812 to 0.876$)$ & $<0.001$ & 0.811 & (0.731 to 0.899 ) & $<0.001$ \\
\hline Wednesday & 0.880 & (0.847 to 0.914$)$ & $<0.001$ & 0.839 & (0.757 to 0.929$)$ & $<0.001$ \\
\hline Thursday & 0.924 & (0.890 to 0.959$)$ & $<0.001$ & 0.930 & (0.841 to 1.028$)$ & 0.155 \\
\hline Friday & 1.000 & - & - & 1.000 & - & - \\
\hline Saturday & 1.109 & (1.067 to 1.153$)$ & $<0.001$ & 1.043 & (0.943 to 1.154$)$ & 0.412 \\
\hline Sunday & 1.053 & (1.014 to 1.094$)$ & 0.007 & 1.006 & (0.908 to 1.114$)$ & 0.910 \\
\hline Significant date & - & - & - & 1.062 & (0.996 to 1.131$)$ & 0.066 \\
\hline \multicolumn{7}{|l|}{ Weather } \\
\hline Maximum temperature $\left({ }^{\circ} \mathrm{C}\right)$ & 1.003 & $(1.000$ to 1.007$)$ & 0.061 & 1.019 & (1.014 to 1.025$)$ & $<0.001$ \\
\hline Minimum temperature $\left({ }^{\circ} \mathrm{C}\right)$ & 0.994 & (0.990 to 0.998$)$ & 0.001 & - & - & - \\
\hline Rainfall (mm) & 1.002 & $(1.000$ to 1.004$)$ & 0.064 & - & - & - \\
\hline Sun (h) & 1.010 & (1.006 to 1.013$)$ & $<0.001$ & 1.030 & (1.022 to 1.038$)$ & $<0.001$ \\
\hline Snow (presence/absence) & 1.079 & (1.044 to 1.115$)$ & $<0.001$ & - & - & - \\
\hline Fog (presence/absence) & - & - & - & - & - & - \\
\hline Mean wind speed (mph) & - & - & - & 1.013 & (1.001 to 1.025$)$ & 0.034 \\
\hline Gust speed (mph) & - & - & - & 0.990 & (0.984 to 0.996$)$ & 0.001 \\
\hline
\end{tabular}

d.f., degrees of freedom; IRR, incidence rate ratio. 
indicator of winter ice and snowfall on adult trauma admissions have not been widely reported elsewhere. Previous work has reported that snowfall had a negative association with trauma admissions ${ }^{3}{ }^{4}$-that is, it resulted in a marked reduction in trauma admissions. The suggestion of the authors of a previous study, ${ }^{4}$ based in the US midwest, was that snow caused a 'siege mentality' resulting in most people remaining indoors. It may be that our modelling procedures, unlike some other studies, allow us to account more fully for the confounding effects of the other weather variables that may mask the more subtle effects of winter cold on trauma admissions. Or it is perhaps more likely that adults in the UK are much less inclined to change their normal day-to-day activities during cold winter weather.

Although it was necessary to exclude some data due to inconsistency of recording, this was a small proportion (6\%) of the full dataset and we have no reason to suspect that this has in any way biased the analysis. Only admission data were available-a more comprehensive analysis would have been obtained by the inclusion of other, less seriously injured, patients also referred to the trauma units. As indicated previously, approximately $10 \%$ of patients included in this study were admitted to a trauma unit after transfer from outside of the immediate locality, and thus the weather data associated with the hospital may not be the same as that experienced by the patient at the location the trauma incident occurred. The effect of this would be to weaken any association between trauma admission counts and weather data in our models; therefore it seems likely that IRR are actually underestimates of their true values. Approximately $7.5 \%$ of the weather data were missing due to instrument technical failure. There is no reason to suspect that this was in any way related to the current weather conditions at the time of failure, therefore it seems unlikely that this could in any way bias or distort the relationships reported in this study. The study results must partly reflect more complex social and economic factors specific to the UK, therefore the results may not readily generalise to other climates and populations.

The results of this extensive study, covering many trauma units of varying size and location over an extensive period of time, show strong and intuitively convincing relationships between recorded weather data and trauma admissions. This model could clearly be used to provide predictions of daily admissions, with clear implications for the scheduling of staff and other resources at UK trauma receiving hospitals; this point has also been noted by a number of other authors, who similarly conclude that their work has implications for seasonal and weather-related adjustment in the management of resources. ${ }^{14} 7$ The use of weather forecasting to predict NHS workload is a topic that has elicited much debate in recent years. ${ }^{8}$ The conclusions of this work are clear and allow us to estimate with some confidence the results of varying weather on UK trauma admission rates. Improvements in data assimilation, modelling and observing systems have all significantly increased the accuracy of both short and medium-range weather forecasts. ${ }^{18} 19$ The challenge for the future is to improve forecast accuracy further in order to provide sufficient time for the detailed planning and allocation of resources that would be necessary to implement these models. If that were possible, the results of these models could have a profound influence on improving the provision of trauma services.

Acknowledgements The authors acknowledge the help of the health research team at the UK Meteorological Office, in particular Christophe Sarran, and also the clinicians and data managers at the following hospitals: Addenbrookes Hospital (Cambridge), Airedale General (Keighley, West Yorkshire), Countess of Chester Hospital (Chester, Cheshire), Hereford County Hospital (Hereford), Hope Hospital (Manchester), Ipswich Hospital (Ipswich), James Cook University Hospital (Middlesbrough), Leeds General Infirmary (Leeds), Leicester Royal Infirmary (Leicester), Lincoln County Hospital (Lincoln), Norfolk and Norwich University Hospital (Norwich), Nottingham University Hospital (Nottingham), Pilgrim Hospital (Boston), Royal Liverpool University Hospital (Liverpool), Royal London Hospital (London), St Helier Hospital (London), St James University Hospital (Leeds), University Hospital of North Staffordshire (Stoke-on-Trent), West Cumberland Hospital (Whitehaven), Whiston Hospital (Merseyside) and Worthing Hospital (Worthing). The authors also acknowledge the help of Tom Jenks, the database manager at TARN, who prepared the trauma admissions dataset.

Funding TARN is funded by annual subscription of NHS trusts.

\section{Competing interests None}

Ethics approval Ethics approval has been granted for research on the anonymised data contained within the TARN by the Patient Information Advisory Group.

Contributors $\mathrm{MO}, \mathrm{FL}, \mathrm{AE}$ and $\mathrm{GP}$ conceived the idea for the work, $\mathrm{AE}$ managed data extraction and validation at TARN and NP undertook all statistical analyses. All authors prepared the manuscript. NP had full access to all of the data in the study and takes responsibility for the integrity of the data and the accuracy of the data analysis.

Provenance and peer review Not commissioned; externally peer reviewed.

\section{REFERENCES}

1. Masterton E, Borton D, O'Brien T. Victims of our climate. Injury 1993;24:247-8.

2. Edwards JB. The temporal distribution of road accidents in adverse weather. Meteorol Appl 1999;6:59-68.

3. Bhattacharyya T, Millham FH. Relationship between weather and seasonal factors and trauma admission volume at a level I trauma center. J Trauma Injury Infec Crit Care 2001;51:118-22.

4. Rising WR, O'Daniel JA, Roberts CS. Correlating weather and trauma admissions at a level I trauma center. J Trauma Injury Infect Crit Care 2006;60:1096-100.

5. Abe T, Tokuda Y, Ohde S, et al. The influence of meteorological factors on the occurrence of trauma and motor vehicle collisions in Tokyo. Emerg Med $\mathrm{J}$ 2008;25:769-72

6. Macgregor DM. Effect of weather on attendance with injury at a paediatric emergency department. Emerg Med J 2003;20:204-5.

7. Atherton WG, Harper WM, Abrams KR. A year's trauma admissions and the effect of the weather. Injury 2005;36:40-6.

8. Met Office Health Forecasting Unit. Forecasting the nation's health: an evaluation by the forecasting unit, Met Office. London: Met Office, 2001.

9. White C. Weather reports to be used to forecast NHS workload. BMJ 2001;323:251.

10. McCullagh P, Nelder JA. Generalized linear models. 2nd edn. London: Chapman and Hall, 1989.

11. Lawless JF. Negative binomial and mixed poisson regression. Can J Stat 1987;15:209-25.

12. Hilbe JM. Negative binomial regression. Cambridge: Cambridge University Press, 2008.

13. R Development Core Team. $R$ : a language and environment for statistical computing. Vienna, Austria: R Foundation For Statistical Computing, 2007. ISBN 3900051-07-0. http://www.R-project.org (accessed 6 Jan 2009).

14. Venables WN, Ripley BD. Modern applied statistics in S-Plus. 2nd edn. New York: Springer, 1997.

15. Akaike H. A new look at the statistical model identification. IEEE Trans Automat Contr 1974;19:716-23.

16. Attia MW, Edwards R. Effect of weather on the number and the nature of visits to a pediatric ED. Am J Emerg Med 1998;16:374-5.

17. Parker MJ, Martin S. Falls, hip fractures and the weather. Eur J Epidemiol 1994; 10:441-2.

18. Simmons AJ, Hollingsworth A. Some aspects of the improvement in skill of numerical weather prediction. $0 \mathrm{~J}$ Roy Meteorol Soc 2002;128:647-77.

19. UK Met Office. How our forecasts have improved. http://www.metoffice.gov.uk/ science/creating/improvements.html (accessed 10 Nov 2009). 


\section{EM]}

\section{Modelling the effects of the weather on admissions to UK trauma units: a cross-sectional study}

Nick Parsons, Michelle Odumenya, Antoinette Edwards, et al.

Emerg Med J 2011 28: 851-855 originally published online November 22, 2010

doi: 10.1136/emj.2010.091058

Updated information and services can be found at:

http://emj.bmj.com/content/28/10/851.full.html

\section{These include:}

Email alerting

Receive free email alerts when new articles cite this article. Sign up in service the box at the top right corner of the online article.

Notes

To request permissions go to:

http://group.bmj.com/group/rights-licensing/permissions

To order reprints go to:

http://journals.bmj.com/cgi/reprintform

To subscribe to BMJ go to:

http://group.bmj.com/subscribe/ 